\title{
PARCELAMENTO E CESSÃO GRATUITA DE SUPERFÍCIE DO SOLO DOMINICAL PARA FINS DE MORADIA EM ÁREAS DE PROTEÇÃO AMBIENTAL: Urbanização e Desenvolvimento Econômico Sustentável
}

http://dx.doi.org/10.21527/2176-6622.2020.53.233-246

Recebido em: 5/12/2019

Modificações solicitadas em: 20/4/2020

Aceito em: 26/4/2020

Sandro Marcos Godoy

Pós-doutorado em Direito pela Università degli Studi di Messina na Itália. Doutorado em Direito - Função Social do Direito pela Faculdade Autônoma de Direito (Fadisp). Mestrado em Direito - Teoria do Direito e do Estado pelo Centro Universitário Eurípides de Marília (Univem). Especialização em Direito Civil e Direito Processual Civil e em Direito Civil (Direito de Família) pela Instituição Toledo de Ensino de Presidente Prudente-SP. Graduação em Direito pela Instituição Toledo de Ensino de Presidente Prudente. É professor permanente do Programa de Mestrado e Doutorado em Direito e da Graduação na Universidade de Marília (Unimar). É professor em diversos cursos da Pós-Graduação em Direito Civil, Direito Processual Civil, Direito Ambiental e Direito do Trabalho. Professor convidado da Assessoria e Desenvolvimento de Projetos (Assesso), do Instituto Brasileiro de Pesquisa Socioeconômico (Inbrape) e do Instituto de Direito Constitucional e Cidadania (IDCC). Advogado da Companhia de Saneamento Básico do Estado de São Paulo (Sabesp). Coordenador da Escola Superior da Advocacia em Presidente Prudente-SP (ESA). Atua nas seguintes áreas: Direito Constitucional, Direito Ambiental, Direito Civil, Direito Processual Civil, Direito do Trabalho e Direito de Família, Direito Tributário e Empresarial. http://lattes.cnpq.br/6172363354073594. https://orcid.org/00000001-8749-395X. sandromgodoy@uol.com.br

Antonio Gilberto Pighinelli Junior

Mestrando em Direito pela Unimar. Especialização em Direito Privado pela Unifor. Graduação em Direito pela Unifor. Curador da Fundação Educacional Araçatuba - FEA. Advogado. http://lattes.cnpq. br/4638670568749038. https://orcid.org/0000-0002-8514-2926. gilberto@gilbertopighinelli.adv.br

\section{RESUMO}

O artigo busca avaliar o parcelamento e cessão gratuita de superfície do solo dominical para fins de moradia como instrumento jurídico de natureza privada para regularização fundiária em Áreas de Preservação Ambiental, colaborando com o Estado enquanto herdeiro de políticas urbanas equivocadas e imediatistas. Utiliza-se o método dedutivo, além da pesquisa bibliográfica e a análise integrada da legislação pertinente, explorando as perspectivas social, ambiental e econômica. A pesquisa tem como objetivo promover uma contribuição com vistas à reformulação de uma nova visão crítica de desenvolvimento baseada na sustentabilidade ambiental. A problematização reside justamente na demonstração da aplicabilidade do parcelamento do solo com cessão gratuita para fins de moradia em área de proteção ambiental, integrando este modelo ao desenvolvimento econômico sustentável. O Ministério do Meio Ambiente afirma que, apesar da existência de leis e instrumentos apropriados, o estágio atual de efetivação de políticas públicas ambientais e urbanas não atende aos requisitos necessários de sustentabilidade, devendo utilizar todos os instrumentos legais disponíveis à harmonização dos direitos fundamentais à moradia, ao meio ambiente equilibrado e o consequente desenvolvimento econômico. Não basta doar ou subsidiar habitações, necessitando contrapartidas da população beneficiada em cumprir seu papel cidadão, participando de programas de educação ambiental como cláusula acidental do contrato, exercitando a posse com consciência ambiental com vistas à sustentabilidade ambiental. Com isso, exige-se do Estado o desenvolvimento de uma avaliação ambiental estratégica que preveja o uso de todos os instrumentos jurídicos aptos a proporcionar um desenvolvimento sustentável urbano inclusivo.

Palavras-chave: Urbanização. Direito de superfície. Moradia. Área de proteção. Sustentabilidade.

\section{FREE LAND SURFACE SUBDIVISION AND ASSIGNMENT FOR HOUSING IN ENVIRONMENTAL PROTECTION AREAS: URBANIZATION AND SUSTAINABLE ECONOMIC DEVELOPMENT}

\section{ABSTRACT}

The article seeks to evaluate the subdivision and free assignment of free land soil surface for housing purposes as a private legal instrument for land tenure regularization in Environmental Protection Areas, collaborating with the State, which is heir to erroneous and immediate urban policies. The deductive method is used, in addition to bibliographic research and integrated analysis of the relevant legislation, exploring social, environmental and economic perspectives. The research aims to promote a contribution to the reformulation of a new critical vision 
of development based on environmental sustainability. The problem lies precisely in the demonstration of the applicability of land parceling with free assignment for the purpose of housing in an environmental protection area, integrating this model to sustainable economic development. The Ministry of the Environment states that despite the existence of appropriate laws and instruments, the current stage of implementation of environmental and urban public policies does not meet the necessary sustainability requirements, and must use all available legal instruments to harmonize fundamental rights to housing, balanced environment and the consequent economic development. It is not enough to donate or subsidize housing, requiring compensation from the benefited population to fulfill their citizen role by participating in environmental education programs as an accidental clause of the contract, exercising possession with environmental awareness with a view to environmental sustainability. Thus, the State is required to develop a strategic environmental assessment which includes the use of all legal instruments capable of providing an inclusive sustainable urban development.

Keywords: Urbanization. Surface right. Dwellng. Protection área. Sustainability.

\section{SUMÁRIO:}

1 Introdução. 2 Compatibilização entre direitos fundamentais, moradia e meio ambiente. 3 Bem dominical e seu parcelamento para fins sociais de moradia em áreas de proteção ambiental: cessão de superfície. 4 Educação ambiental: cláusula acidental do contrato de cessão de uso de superfície de bens dominicais. 5 Desenvolvimento urbano e econômico sustentáveis em áreas de proteção ambiental. 6 Conclusão. 7 Referências.

\section{INTRODUÇÃO}

O direito social de moradia, enquanto fundamental de segunda geração, positivado na Carta Constitucional de 1988 como prerrogativa de existência digna do cidadão, sujeita o Estado à efetivação de ações positivas que possibilitem a autoaplicabilidade da norma, beneficiando aqueles que necessitem de condições básicas de teto.

Problema de grande complexidade, especialmente quando observada a fixação humana em áreas de proteção ambiental. A quase utópica missão de proporcionar a todos uma moradia digna nos termos do que dispõe a lei maior, é um desafio que exige a atuação pontual e contínua do Estado nesse sentido. Temos no desenvolvimento urbano/econômico, fenômeno que atinge diretamente o meio ambiente, direito fundamental de terceira geração e, não raro, por sua relevância, a proteção ambiental finda por interferir diretamente no exercício do uso do solo.

Não se pode, todavia, associar forçosamente a urbanização ao aumento dos impactos ambientais, na medida em que vários e diferentes fatores endógenos contribuem para a significativa degradação ambiental que se tem presenciado na geração atual.

O tema do artigo busca colaborar, dentre as muitas ferramentas disponíveis para auxiliar na construção de caminhos que promovam a alteração da matriz urbanística, para a promoção da justiça socioambiental e espacial.

Não se pode negar o fato de que a integração homem e natureza está intrinsecamente ligada a potenciais desequilíbrios ambientais, quando não raro a danos efetivos, porém simplesmente limitar o assentamento humano não os inibe e, tampouco, colabora diretamente para a preservação ambiental.

Favelização, ausência de saneamento e fornecimento de água e energia, dano à fauna e à flora, são consequências de atos de gestão meramente restritivos, afetando diretamente a dignidade humana e o desenvolvimento econômico no entorno do solo irregularmente utilizado. Faz-se necessário regulamentação, fiscalização e intervenção positiva do Estado no sentido de harmonizar tais direitos, inclusive relativizando a ideia de que as Áreas de Proteção Ambiental não devem ter outra destinação.

Ao instituir referidas áreas, o legislador disciplinou a conjugação desses dois direitos fundamentais moradia e meio ambiente sustentável. Utilizando o método dedutivo e conjugando com a pesquisa legislativa e bibliográfica, objetiva-se abordar a responsabilidade do Estado em usar seus bens dominicais para o alcance do fim social urbanístico, utilizando o parcelamento e a cessão de superfície do solo como ferramentas jurídicas para alcançar eficiência e eficácia na fixação formal do homem ao meio ambiente urbano.

Revela-se necessário considerar as questões administrativas e ambientais envolvidas quanto ao cumprimento equitativo das normas entre as partes - governante/governado -, requisito de eficácia plena para a efetivação da cessão do uso do bem público ao particular. 
A problematização da pesquisa envolve as questões de políticas públicas inclusivas de urbanização e seus efeitos positivos ao desenvolvimento econômico, evidenciando que é possível, com base na estrutura jurídica existente, fomentar cenários em que a dignidade humana e o meio ambiente sustentável devem coexistir como fonte contínua de geração de riquezas para as atuais e futuras gerações.

Em princípio, ocupação urbana e preservação ambiental não são excludentes e podem coexistir desde que se adotem políticas públicas inclusivas de educação ambiental, quando o homem passe a ser protagonista de uma reflexão sobre a natureza da sustentabilidade ambiental em compasso com o desenvolvimento urbano.

\section{COMPATIBILIZAÇÃO ENTRE DIREITOS FUNDAMENTAIS, MORADIA E MEIO AMBIENTE}

A Constituição Federal de 1998 (BRASIL, 1988) elenca, em sua estrutura, Direitos Fundamentais baseados em valores históricos que referenciam e orientam seu sentido, e essa noção de ordem, permeada de valores, traduz os anseios dos jurisdicionados e inspira o Estado Democrático de Direito à efetivação de tais preceitos, exigindo exercício lógico para compreender seu significado e finalidades ao aplicá-los por meio de ações negativas ou positivas.

Em uma cronologia histórica, é possível sustentar três momentos de ebulição desses princípios fundamentais denominados dimensões, como perspectiva de sua importância e influência no tempo.

Os direitos fundamentais de primeira dimensão tratam das liberdades civis, exigindo do Estado respeito à autonomia individual, consagrando tais liberdades por meio da não interferência estatal em seu desenvolvimento. Surgia, em meados do século 18, o Estado de Direito Liberal, disciplinando a disputa entre o Poder e a liberdade, reflexo da relação entre o absolutismo e o individualismo, tendo adquirido como principal função a defesa da liberdade (BONAVIDES, 2001).

No início do século 20 a Constituição de Weimar/1919 suscita os chamados direitos fundamentais econômicos e sociais, fruto dos efeitos do pós-guerra e orientados pelo ideal de Estado Democrático Social. A Constituição alemã albergava a defesa da dignidade da pessoa humana, garantindo na perspectiva individual direitos civis e políticos e, numa ordem de grupos, os direitos econômicos e sociais. Surgia a segunda dimensão dos direitos fundamentais, e nela a consciência da necessidade de uma Ordem de direitos pautadas nos ideais de igualdade, em que anseios coletivos exigiam a proteção do Estado.

Dessa igualdade, contrariamente à não intervenção estatal originada do Estado Liberal, exige-se que este atue promovendo o bem-estar social considerando que os direitos econômicos e sociais demandam do Estado uma atitude positiva, prestacional e, em certa medida, intervencionista.

Na virada da primeira metade do século 20, experimentado os terríveis efeitos da Segunda Guerra Mundial, a solidariedade apresentou-se no âmbito dos direitos fundamentais como valor complementar aos ideais de liberdade e da busca pela igualdade, numa dimensão marcada agora por direitos que exigem um dever solidário, ou seja, não apenas direitos, mas também deveres por parte dos titulares que integram a Ordem dos direitos fundamentais.

Da exigência desse comportamento ético solidário, a cidadania volta-se para a conquista dos direitos relacionados a interesses coletivos e difusos, chamados de direitos de terceira dimensão, tendo o meio ambiente como seu maior expoente.

Superada a exposição da perspectiva jurídica dimensional histórica dos direitos fundamentais, superficial, mas necessária ao presente estudo, direciona-se o foco aos direitos de moradia e meio ambiente equilibrado, explorando como ambos podem e devem se conciliar mediante a atuação positiva dos atores envolvidos - o individual e o difuso.

Como visto, os direitos sociais destinam-se a garantir ao cidadão o básico necessário para viver dignamente. São prerrogativas que não se sustentam somente no texto frio da lei, mas que exigem uma atitude do Estado de forma a efetivá-los, proporcionando o bem-estar social tão almejado e a redução das desigualdades sociais e econômicas.

Denominados direitos de segunda dimensão, os Direitos Sociais atrelam-se à necessidade de o Estado agir intervindo diretamente na sociedade para a efetivação dos ideais de dignidade. 
Assim, "ao contrário dos direitos de primeira geração, em que o Estado passa a ter o dever de não intervir, nos direitos de segunda geração o Estado passa a ter responsabilidade preponderante para a concretização de um ideal de vida digno na sociedade" (PAULO; ALEXANDRINO, 2012, p. 102).

Para Moraes (2017, p. 209):

Direitos sociais são direitos fundamentais do homem, caracterizando-se como verdadeiras liberdades positivas, de observância obrigatória em um Estado Social de Direito, tendo por finalidade a melhoria de condições de vida aos hipossuficientes, visando à concretização da igualdade social, e são consagrados como fundamentos do Estado democrático, pelo art. 1ํ, IV, da Constituição Federal.

Ao versar sobre Direitos e Garantias Fundamentais, e também sobre os Direitos Sociais, o legislador editou a Emenda Constitucional no 26, incluindo o direito à moradia no rol previsto no artigo 60 da Carta Magna. Uma das necessidades mais básicas do ser humano, tratada formalmente desde 1948 na Declaração Universal dos Direitos Humanos, somente tornou-se cláusula pétrea explícita nos idos de 2000.

A constitucionalização do dito direito, ante a sua natureza e autoaplicabilidade, impõe ao Estado grandes desafios exigindo a instituição de políticas públicas de habitação visando a garantir teto digno para todos, especialmente aos menos favorecidos e vulneráveis. Por sua vez, soma-se ao conceito de moradia a necessária disciplina urbanística e, dentre seus vieses, o saneamento básico como medida inclusiva de desenvolvimento social e econômico.

Na perspectiva de atuação positiva, quando falamos de Estado, o texto constitucional é claro ao delegar competência comum a todos os seus entes, para "promover programas de construção de moradias e a melhoria das condições habitacionais e de saneamento básico" nos termos dispostos no artigo 23, inciso IX.

Em vista da concretude do direito ora estudado, e pelo induvidoso dever do Estado em promover e introduzir, de forma direta ou indireta, políticas públicas habitacionais, este visa o resgate da dignidade e a inclusão social do cidadão por meio de atos efetivos nesse sentido e, mais além, o fazer de forma sustentável, garantindo sua realização e observando os ditames de direito ambiental, vinculando e estimulando, por intermédio dos instrumentos utilizados, atitudes solidárias dos beneficiários.

O aspecto solidário é marca determinante nos chamados direitos fundamentais de terceira geração. Evocam o destino da humanidade e as questões relacionadas ao Meio Ambiente, sua proteção e conservação, sem se desapegar ao necessário desenvolvimento econômico.

Nasce aqui uma consciência jurídica de grupo, redimensionando os direitos coletivos, ora denominados Direitos Transindividuais ou Difusos. Esse olhar para o futuro traduz o sentimento jurídico de solidariedade, ultrapassando a proteção da qualidade de vida da sociedade atual para, assim, assegurar o mesmo bem-estar para as futuras gerações, que afeta a todos na busca pela sustentabilidade e perenidade.

A ideia de desenvolvimento sustentável, expressão criada em 1972 em Estocolmo na Conferência Mundial de Meio Ambiente, define-se em atender às necessidades do presente sem comprometer a capacidade das gerações futuras de responder às suas próprias necessidades, conciliando as atividades econômicas, sociais e a preservação do Meio Ambiente (GODOY, 2020).

Dessa forma, é possível inferir que o pensar sustentável deve se revelar por meio de ações: “[...] energéticas, informacionais, físico-químicas que sustentam todos os seres, especialmente a Terra viva, a comunidade de vida e a vida humana, visando a sua continuidade e ainda atender às necessidades das gerações presentes e futuras [...] (BOFF, 2012, p. 165).

A Constituição Federal de 1988 (BRASIL, 1988), ao dispor sobre a Ordem Social, estabelece por objetivo o bem-estar e a justiça social, discorrendo, no capítulo II, artigo 225, que "todos têm direito ao meio ambiente ecologicamente equilibrado, bem de uso comum do povo e essencial à sadia qualidade de vida, impondo-se ao Poder Público e à coletividade o dever de defendê-lo e preservá-lo para as presentes e futuras gerações".

É possível tomar como conceito amplo que o meio ambiente é o sistema formado por elementos naturais e artificiais relacionados entre si e que são modificados pela ação humana. Trata-se do meio que condiciona a forma de vida da sociedade e que inclui valores naturais, sociais e culturais que existem num determinado local e momento, composto tanto por coisas que possuem ou não possuem vida. 
A Lei no 6.938/81, que institui a Política Nacional do Meio Ambiente, conceitua meio ambiente como "o conjunto de condições, leis, influências e interações de ordem física, química e biológica, que permite, abriga e rege a vida em todas as suas formas", conceito este recepcionado pelo artigo 225 da CF/88, que eleva o meio ambiente à condição de direito de todos e bem de uso comum do povo.

Como visto, em razão da alta relevância do bem jurídico tutelado, estabeleceu o legislador a obrigação equitativa do Poder Público e da Comunidade de preservá-lo para as presentes e futuras gerações (ANTUNES, 2017).

Analisado os direitos fundamentais de moradia e meio ambiente sustentável, doravante é possível discorrer sobre o cenário jurídico e a compatibilização desses institutos que comungam com a Área de Proteção Ambiental.

Instituída pela Constituição Federal (BRASIL, 1988) e, especialmente, pela Lei Federal no 9.985/2000, Área de Proteção Ambiental é o espaço destinado ao uso e convívio sustentável do homem junto a natureza, pelo menos em tese (GODOY, 2020).

As Áreas de Proteção Ambiental (APA) são unidades de conservação estabelecidas em regiões já habitadas, tendo como um de seus objetivos precípuos o de assegurar o bem-estar das populações humanas que nela vivem. A conjugação do bem-estar humano ao aprimoramento das condições ambientais existentes no interior da APA, todavia, é o objetivo maior do instituto.

É neste sentido que se desenvolve este trabalho, uma vez que é permitido a habitação e atividades produtivas nestas áreas que outrora se mostram subutilizadas. A questão encerra-se na gestão do uso do solo de áreas dominicais ociosas e no desenvolvimento de políticas públicas de habitação que eliminem situações humanas e ambientais degradantes, fenômeno que impacta diretamente a sustentabilidade inspiradora da legislação que disciplina o tema.

Cumpre ao Estado dispor de suas terras para a ocupação e regularização fundiária urbana, tendo no parcelamento e cessão do uso do solo dominical para fins sociais de moradia, instrumentos jurídicos efetivos a tal fim.

As Áreas de Proteção Ambiental são geridas necessariamente por uma entidade ambiental encarregada de assegurar o atendimento das finalidades da norma instituidora, buscando alcançar a sustentabilidade ambiental definida consistente em efetivar condições dignas de moradia ao cidadão, fomento à consciência cidadã ecológica e, por meio do processo de urbanização, estimular o desenvolvimento econômico, o qual também se afigura como um direito fundamental a ser resguardado, desde que executado nos moldes estabelecidos no plano de manejo e de maneira sustentável.

Não é demais alinhar ao pensamento ora exposto a ideia de função social da propriedade reconhecida na legislação constitucional e infraconstitucional como sendo aquela que propõe a interface da propriedade ao benefício social que dela pode fluir.

\section{BEM DOMINICAL E SEU PARCELAMENTO PARA FINS SOCIAIS DE MORADIA EM ÁREAS DE PROTEÇÃO AMBIENTAL: CESSÃO DE SUPERFÍCIE}

Bens públicos são aqueles pertencentes a pessoas jurídicas de direito público interno nos termos do critério empregado pelo Código Civil em seu artigo 98, seguindo a regra de que é a natureza jurídica do sujeito, do proprietário, do dono, que pauta a natureza do bem em seu patrimônio. São públicos os bens da União, dos Estados, do Distrito Federal, dos territórios, dos municípios, das autarquias, inclusive das associações públicas e de todas as entidades que venham a ser criadas por lei com natureza de pessoa jurídica de direito público interno.

Divide-se em categorias de acordo com sua natureza e destino, sendo relevante ao tema abordar os bens públicos dominicais, patrimônio público disponível e sem afetação, definido pela lei civil como bens "que constituem o patrimônio das pessoas jurídicas de direito público, como objeto de direito pessoal, ou real, de cada uma dessas entidades", podendo ser utilizado, desde que autorizado a todos, os usos em direito admitidos, observada a compatibilidade com o interesse público e a finalidade da entidade pública a que tais bens pertencem. 
Essa flexibilidade no uso, decorrente da não afetação, não retira da gestão de tais bens o dever obrigatório de produzir utilidades públicas, contribuindo para a consecução dos interesses envolvidos, destinando seu uso em benefício comum.

Exige-se o interesse público e a legalidade no trato dos bens dominicais, inclusive quanto à possibilidade de sua alienação ou outorga para uso exclusivo de terceiro. Tais atos efetivam-se por instrumentos privados como exige a lei civil, por exemplo, a constituição de direito real de uso ou direito real de superfície, contrato de cessão de uso, sujeitando-se, assim, a ser constituído como objeto de relações obrigacionais e reais firmadas pelo ente público junto ao particular.

O bem público dominical deve destinar-se a cumprir sua função social - ser útil e produtivo -, sendo gerido e utilizado no melhor proveito do interesse público.

Neste sentido, Marques Neto (2009, p. 222) entende ser

[...] imperativo o emprego econômico dos bens dominicais de forma a que eles cumpram a finalidade de gerar receitas para a Administração Pública. Isso não apenas pelo sobredito princípio da função social da propriedade (que interdita a ociosidade, a não utilização de bens), mas também pelo princípio da economicidade, consagrado também pela Constituição e objeto de tutela pelos Tribunais de Contas (art. 70, caput, CF).

Podemos afirmar também que a ociosidade do bem pode, e deve ser, suprida por usos não econômicos de natureza social, comuns ou privativos e, partindo da premissa de que todo bem estatal deve produzir alguma utilidade social, o uso de bens públicos dominicais destinados à urbanização e moradia não foge à regra, especialmente entendendo-se que o direito ao teto é um direito fundamental social.

A ideia que ora se discute é a instrumentalização de tal direito, e as APAs, por sua natureza e constituição, comumente concentram terras públicas sem uso cujo parcelamento urbano prévio é ação necessária à posterior cessão para utilização de superfície dos bens dominicais destinados à regularização fundiária, sendo certo que hoje a Federação possui 125 APAs constituídas e distribuídas em 22 Estados.

O uso da superfície é negócio jurídico privado disciplinado tanto pelo Código Civil quanto pelo Estatuto das Cidades, Lei no 10.257/2001, consubstanciado no direito do proprietário de poder conceder a outrem o direito de construir ou de plantar em seu terreno, por tempo determinado, mediante escritura pública, de forma gratuita ou onerosa, podendo, ainda, ser constituído por pessoa de direito público interno.

Dentre os vários objetivos do instituto pode-se destacar o estímulo ao uso de imóveis desocupados e à resolução de crises habitacionais, revelando realmente a função social da propriedade almejada pelo legislador constitucional.

O interessado, chamado de superficiário, passa a aproveitar o terreno que não era de sua propriedade, possibilitando o desdobramento do direito real de propriedade, otimizando o uso e o aproveitamento dos espaços urbanos, equilibrando os interesses públicos - função social -, e particular - moradia (GOMES, 2002).

É possível utilizar o conceito doutrinário de direito de superfície no sentido de que é "direito real de gozo ou fruição, direito de plantar ou edificar em terreno de propriedade alheia, chamado de direito de implante. De uma forma bem clara, trata-se de uma concessão do solo" (VENOSA, 2006, p. 222).

A natureza jurídica do instituto finda em um direito real autônomo em que, concedido, o edifício construído pertence exclusivamente ao superficiário, enquanto o solo continua a pertencer ao seu proprietário.

A ocupação de áreas de proteção ambiental não é fenômeno raro a exigir do poder público providências no sentido de sua regularização e controle. Não se aborda aqui construções de casas de veraneios e outras investidas privadas aptas a satisfazer o conforto de minorias.

Trata-se da necessidade de proporcionar moradias condignas para uma grande parcela da população que, espremida pelo desenvolvimento urbano, sem alternativas viáveis, se assenta em terras de propriedade do Estado localizada em regiões onde, quer pelas limitações de acesso, quer por restrições históricas, restaram até então sem uso e ocupação.

São os processos de favelização observados nas grandes cidades e que se estendem atualmente por praticamente todas as urbes do território nacional, fruto da ausência de políticas públicas consistentes e perenes. 
Cumpre ao Estado dedicar uma atenção maior às áreas de proteção ambiental em razão da fragilidade de seus biomas e da sustentabilidade esperada decorrente da integração homem natureza, posto que esse instituto jurídico permite sua coexistência. Essa sustentabilidade vai decorrer necessariamente da observação plena das normas pelas partes envolvidas em um cenário de responsabilidade equitativa.

O instrumento da cessão de uso de superfície revela-se um mecanismo educador vinculante do superficiário vulnerável quando no exercício de seus direitos e, especialmente, de suas obrigações em relação ao meio ambiente em que habita e, por outro lado, exige do Estado cessionário a efetivação de ações urbanísticas necessárias à sua preservação, conferindo um maior poder de fiscalização.

Embora trate-se de direitos reais, pode ser rescindido em casos de não observância das especificações do uso a que se destina o imóvel localizado em uma Área de Proteção Ambiental.

Como dispõe a Lei no 9.985/2000 em seu artigo 15, a "Área de Proteção Ambiental é uma área em geral extensa, com um certo grau de ocupação humana, dotada de atributos abióticos, bióticos, estéticos ou culturais especialmente importantes para a qualidade de vida e o bem-estar das populações humanas, e tem como objetivos básicos proteger a diversidade biológica, disciplinar o processo de ocupação e assegurar a sustentabilidade do uso dos recursos naturais."

Neste sentido, "[...] a APA tem por finalidade, continuando a tradição do regime legal anterior, a garantia da qualidade de vida humana, por suposto; isso implica que ela deve, necessariamente, ser uma área ocupada por seres humanos" (ANTUNES, 2017, p. 984).

A APA poderá ser estabelecida em área de domínio público ou privado pelos entes da Federação e, embora de natureza jurídica restritiva, comporta em sua área outras unidades de conservação, ecossistemas urbanos, oportunidade para se experimentar técnicas e atitudes que conciliem o uso da terra e o desenvolvimento regional com a manutenção dos processos ecológicos essenciais, além de uma gestão participativa representada por um conselho composto por representantes dos órgãos públicos, de organizações da sociedade civil e da população residente (PORTANOVA; OLAVO LEITE; FIGUEIREDO, 2015).

Conhecendo esses três institutos jurídicos - bens públicos dominicais, cessão de superfície e áreas de proteção ambiental -, pode-se concluir que o Estado tem ferramentas suficientes para instituir políticas públicas de regularização de ocupações em áreas ambientalmente protegidas.

Antes, porém, será necessário refletir sobre as condições do direito à moradia no cenário urbano brasileiro, decorrente do crescimento desordenado das cidades e da morosidade na instalação de políticas públicas e os impactos sociais e ambientais decorrentes.

A precarização da habitação em APA decorre, na maioria das vezes, em virtude da ausência de poder aquisitivo da população de baixa renda para se inserir no mercado imobiliário formal, sendo direcionada para as áreas impróprias ou de uso limitado, acarretando naturalmente impactos ambientais.

Acrescente-se o crescimento demográfico da própria área protegida, como no caso do arquipélago de Fernando de Noronha, impondo a regularização urbana por meio da cessão de terrenos destinados à moradia.

O parcelamento e a cessão do uso da superfície do solo revelam-se um poderoso instrumento de regularização fundiária em APA. O fato de o Estado transferir apenas o direito real de uso da superfície, regularizando construções irregulares ou fomentando a construção regular de habitações, demanda necessariamente melhorias urbanísticas e ambientais, estimulando, ainda, o desenvolvimento econômico de seu entorno.

Por sua vez, o Estatuto das Cidades direciona a ação do Estado no sentido de efetivar a regularização fundiária e a urbanização de áreas ocupadas por população de baixa renda, considerando a situação socioeconômica da população e as normas ambientais, além de permitir a simplificação da legislação de parcelamento, uso e ocupação do solo e das normas edilícias para tal fim.

Dada a natureza privada do contrato de cessão de uso dos direitos de superfície, o administrador público poderá constituir cláusulas que vinculam o superficiário à conscientização ambiental sobre o solo que ocupa, somado às próprias normas derivadas do plano de manejo da área, de forma que a não observância das regras impõe a perda desse direito e, consequentemente, de tudo aquilo que fora ali fixado.

Partindo, todavia, de pesquisas em situações análogas, os resultados mostram que populações em tal situação são conscientes e favoráveis a ações sustentáveis na medida em que, muitas vezes, é o próprio meio ambiente em que estão inseridas que lhes proporcionam os meios de subsistência (LISBOA PESSOA, 2014). 
Evidenciada a responsabilidade de preservação que nasce com a regularização fundiária e a satisfação do direito à moradia digna por meio da atuação positiva do Estado nesse sentido, a este cabe cumprir todas as obrigações atinentes ao desenvolvimento urbano sustentável, especialmente detendo instrumento jurídico legítimo e eficaz de controle do uso da posse.

Trata-se da responsabilidade equitativa. Se por um lado ao Estado cumpre agir no sentido de efetivar direitos fundamentais de moradia e a um meio ambiente equilibrado, ao cidadão compete observar estritamente as normas que regem sua inserção nesse meio ambientalmente protegido, até porque dele depende a própria subsistência humana (GODOY, 2017).

É neste contexto que a educação ambiental flui como instrumento de integração da ideia de que o homem pode ocupar os espaços de APAs, desde que ciente da sua responsabilidade social.

\section{EDUCAÇÃO AMBIENTAL: CLÁUSULA ACIDENTAL DO CONTRATO DE CESSÃO DE USO DE SUPERFÍCIE DE BENS DOMINICAIS}

O meio ambiente urbano é resultado da integração do "sistema natural" e do "sistema antrópico", sendo o primeiro composto pelo meio físico e biológico, ou seja, solo, vegetação, animais, água, dentre outros elementos, e o segundo pelas ações humanas e suas consequentes relações sociais e culturais.

Ao atrelarmos o conceito de sustentabilidade, buscamos disciplinar as ações do homem e seus impactos nesses sistemas, tendo por objetivo a perenidade de seus elementos considerando as perspectivas econômica, social e ambiental.

A participação do Estado para a consecução dos direitos à moradia e um meio ambiente equilibrado, exige ações necessárias para se alcançar a sustentabilidade urbana, posto ser nesse ambiente que se observa naturalmente o desenvolvimento econômico e social. Desenvolver cidades sustentáveis exige mudanças fundamentais no comportamento humano, na prática do poder público, no comércio, na arquitetura e no planejamento (ROGERS, 2005).

A gestão governamental de ocupação do solo deve estar atenta aos prejuízos ambientais que prejudicam diretamente o homem e os demais elementos do ambiente em que ele se insere, fomentando o desenvolvimento de um comportamento ético entre as partes envolvidas - Estado, população, organização civil -, delineando direitos e deveres como forma de possibilitar a construção de um meio ambiente urbano sustentável.

A simples edição de leis não basta para a consecução de tal objetivo. Exige-se um exercício contínuo e mútuo facilitado, todavia, pela efetividade conferida aos instrumentos jurídicos que disciplinam as relações do uso do solo e dos processos de urbanização em áreas protegidas.

A permissão da presença humana em APA deve se fundar na premissa da harmonia de direitos fundamentais - moradia, meio ambiente equilibrado e desenvolvimento econômico -, abrigando e protegendo a vida humana em sua concepção e padrões de dignidade sem desproteger as demais formas de vida e recursos ambientais, posto que a preservação do meio ambiente somente faz sentido para o bem da espécie humana (GODOY, 2017).

A Constituição Federal (BRASIL, 1988) preceitua, em seu artigo 182, os objetivos da política de desenvolvimento urbano, destacando as funções sociais da cidade e o bem-estar de seus habitantes. No mesmo sentido, o Estatuto da Cidade, Lei no 10.257/01, estabelece normas de ordem pública e interesse social que regulam o uso da propriedade urbana em prol do bem coletivo, da segurança e do bem-estar dos cidadãos, bem como do equilíbrio ambiental. Normas existem, exigindo a instrumentalização de ações do Estado nesse sentido.

Esse poder-dever de agir deve materializar-se mediante ações práticas palpáveis e integradas num contexto jurídico que permita o desenvolvimento de políticas efetivas de conscientização ambiental e controle das ações do homem inserido em áreas de proteção.

Se partimos da premissa de que o emprego do contrato de cessão de uso de superfície é uma ferramenta efetiva para a gestão do Estado para a utilização do solo urbano fincado em APA, ante a natureza privada do instrumento jurídico e sua flexibilidade no que respeita aos objetivos acessórios que se possam estabelecer 
para sua efetiva validade e consecução, sob pena de rescisão e retomada do bem, são nessas cláusulas que residirá os fatores de sucesso para se alcançar comportamentos que tornem sustentável a convivência homem e natureza nessas áreas.

O objeto central do contrato de cessão de direitos de superfície basicamente transfere ao particular a permissão de uso do solo em que, eventualmente, se encontre morando de forma irregular e/ou o fixe em área previamente individuada. Pode-se, todavia, atrelar ao negócio jurídico cláusulas acidentais visando a determinar a eficácia do que restou pactuado.

Os elementos acidentais do negócio jurídico são aqueles "que se lhe acrescentam com o objetivo de modificar uma ou algumas de suas consequências naturais" (DINIZ, 2006, p. 435); podem revestir-se de natureza unilateral ou bilateral com objetivos de exigibilidade, retardamento do nascimento de aquisição ou de restrição de certo prazo.

Dada a possibilidade da bilateralidade no estabelecimento das condições, termos e encargos, a constituição de elementos acidentais no contrato de cessão de uso de superfície de terras dominicais, busca equilibrar as relações Estado-Cidadão numa perspectiva de construir cooperação e corresponsabilidades.

O primeiro elemento acidental condicionante à eficácia do negócio jurídico sugerido no presente estudo, é o que preveja a necessária participação do superficiário em programas de educação ambiental a serem instituídos pelas entidades administrativas da APA em conjunto com o poder público, desenvolvidos de forma estruturada e pontual.

A Lei no 9.985/2000, que regulamenta o artigo 225 da Constituição Federal (BRASIL, 1988), institui o Sistema Nacional de Unidades de Conservação da Natureza, dispondo, em seu artigo 15, parágrafo 5으, que a Área de Proteção Ambiental disporá de um Conselho presidido pelo órgão responsável por sua administração, constituído por representantes dos órgãos públicos, de organizações da sociedade civil e da população residente. Ou seja, existe equipamento estatal para executar ações de educação ambiental.

"A educação ambiental é o caminho que conduz essa nova geração a identificar valores importantes para a sua própria existência e mantença da vida humana em uma sociedade com consumo praticamente ilimitado" (GODOY, 2017, p. 77).

O objetivo dessa cláusula acidental é reduzir os custos ambientais a longo prazo, fomentando na população a postura de guardiã do meio ambiente e de consciência ecológica no uso da terra recebida, participando, de forma solidária, na preservação do meio urbano na qual encontra-se inserida, revestindo seus fins no desenvolvimento de uma cultura de caráter natural, não antropocêntrico, em que a reciprocidade entre os seres humanos e a terra que os provê exige um constante cuidar e preservar.

A educação ambiental fora objeto de disciplina na Lei no 9.795/99, conceituada como os processos por meio dos quais o indivíduo e a coletividade constroem valores sociais, conhecimentos, habilidades, atitudes e competências voltadas para a conservação do meio ambiente, bem de uso comum do povo, essencial à sadia qualidade de vida e sua sustentabilidade, destacando como princípios o enfoque humanista, democrático, concebendo o meio ambiente em sua totalidade - meio natural, socioeconômico e cultural -, sob o enfoque da sustentabilidade.

Deriva de ordem constitucional que impõe ao Estado promover e orientar a educação ambiental em todos os níveis de ensino e a conscientização pública para a proteção do meio ambiente.

No caso, desenvolver um programa efetivo voltado para as necessidades da APA, na qual se encontre residindo o superficiário, é o fator principal de sucesso na efetivação do uso sustentável dos recursos, tratando-se de um instrumento de integração social na defesa do meio ambiente.

A Educação Ambiental tem por fim o desenvolvimento de uma compreensão integrada do meio ambiente em suas múltiplas e complexas relações, envolvendo aspectos ecológicos, psicológicos, legais, políticos, sociais, econômicos, científicos, culturais e éticos e o fortalecimento da cidadania, autodeterminação dos povos e solidariedade como fundamentos para o futuro da humanidade.

A simples transcrição do texto legal fortalece a ideia de incluir no contrato de cessão de uso de superfície de solo dominical uma cláusula condicional mediante a participação efetiva do superficiário em programas de educação ambiental e, por sua vez, implicando necessariamente a atuação do Estado em prover cursos para este fim, sob pena de fragilizar sua atuação na consecução do negócio jurídico. 
A educação ambiental deve colaborar para a superação do conceito clássico de cidadania liberal centrada nos direitos civis do cidadão, evoluindo para um pensar cidadão ecológico, responsável, com deveres e protagonista na condução de mudanças socioambientais sustentáveis, desenvolvendo um senso crítico que Ihe permita questionar injustiças ambientais, desde a privação de direitos, como moradia e meio ambiente sustentável, até eventuais limitações à livre-iniciativa (BECK, 2011).

Deve despertar a consciência para o necessário equilíbrio entre os direitos e responsabilidades individuais e coletivos e prioridades econômicas e ambientais, exigindo, por sua vez, que o Estado atue prontamente nos seus deveres para o desenvolvimento de um meio ambiente urbano sustentável.

"O conceito de cidadania em nossos dias não mais está restrito à dimensão exclusivamente política expressa no binômio: votar e ser votado. Necessariamente vai além, incorporando o conteúdo de participação na vida da sociedade [...]" (JUCÁ, 2011, p. 31).

A educação ambiental como educação política prioriza a ética e enfatiza antes a questão do "por que" fazer para depois perguntar "como" fazer. Ela contribui para que os cidadãos possam refletir e exigir justiça social, cidadania, autogestão e ética nas relações sociais e com a natureza (JACOBI, 1998).

Assim, está "impregnada da utopia de mudar radicalmente as relações que conhecemos hoje, sejam elas entre a humanidade, sejam entre esta e a natureza" (REIGOTA, 1998, p. 14).

Entendido que a cessão do uso do direito de superfície de bens dominicais pelo Estado é uma alternativa viável para o processo de regularização fundiária e que pode ser inserido nas APAs, condicionado a ações de educação ambiental que estimulem o pensamento cidadão sustentável e solidário, o artigo 3이 da CF estabelece que o uso desse solo e sua edificação deverá naturalmente seguir os fundamentos direcionados à dignidade da pessoa e ao bem-estar da coletividade, cumprindo, assim, a função social da propriedade estatal.

Por outro lado, esta ideia possibilitará obrigatoriamente o desenvolvimento urbano econômico sustentável nas áreas de APAs, que se revela interesse do próprio Estado, inclusive para a geração de receitas e arrecadação de tributos.

\section{DESENVOLVIMENTO URBANO E ECONÔMICO SUSTENTÁVEL EM ÁREAS DE PROTEÇÃO AMBIENTAL}

Os padrões de urbanização adotados no mundo desde a Revolução Industrial, tornaram-se insustentáveis ante os ciclos de crescimento econômico e urbano, demandando soluções que otimizem o tratamento do lixo, a emissão de efluentes sanitários e industriais, a impermeabilização e a erosão do solo, o consumo de energia, a perda das fontes de água doce e os danos à fauna e à flora, gerando um passivo ambiental urbano que se agrava diante das desigualdades econômicas e sociais.

Essas desigualdades restringem o acesso à propriedade da terra, fomentando a precariedade habitacional e a informalidade urbana, exigindo políticas públicas que estimulem a realização no plano urbano da justiça socioambiental.

Cabe ao Estado o controle sobre a ocupação do solo, a regularização fundiária, a urbanização das áreas urbanas precárias e a provisão habitacional, que utiliza novas tecnologias e recursos que minimizem o impacto ambiental decorrente desses processos. Trata-se de obrigações fundamentais.

A questão da "sustentabilidade urbana" deve ser entendida como a busca prioritária pela justiça socioambiental e, para que ganhe legibilidade, é necessário construir, na agenda política e social, uma matriz única e abrangente de compreensão da questão, com o desafio de construir cidades ambiental e socialmente justas para as próximas gerações (NUNES et al., 2015).

Não se trata aqui de exigir do Estado a distribuição de unidades habitacionais de forma irresponsável apenas para suprir um déficit de desigualdade, mas ceder o uso da superfície de terras dominicais mediante contrapartida cidadã, conforme exposto no tópico anterior, subsidiando a construção de imóveis que se adequem às exigências das normas previstas no plano de manejo das APAs.

Nesse sentido, não basta ceder o uso da superfície, pois, em se tratando de regularização fundiária e urbanização de áreas precárias, exige-se o financiamento de habitação para que o direito de moradia se efetive. 
Um dos passos para a elaboração de uma agenda de justiça socioambiental destacado no documento "Habitação Social e Sustentabilidade", é a promoção dos investimentos públicos destinados à habitação de interesse social (HIS). Segundo o estudo, é comum termos menos de 3\% dos orçamentos das metrópoles destinados ao setor habitacional, embora a falta de moradia atinja uma parcela considerável de suas populações.

Os empecilhos financeiros ainda são apresentados como significativos obstáculos ao urbanismo e desenvolvimento sustentável. Para dominar essas dificuldades, sugere-se duas ações: Mudança na Legislação e Vinculação de Recursos. A modificação da estrutura legal, com o objetivo de especificar com grande grau de aprimoramento como precisam ser financiadas e instituídas tais ações, aumenta a vinculação dos recursos públicos e o real uso dos recursos já pressupostos em lei na realização de programas habitacionais sustentáveis.

Esses recursos, todavia, não devem ser destinados sem uma contrapartida social justa da população que o recebe, esperando a sociedade em geral uma atuação responsável dos superficiários no sentido de manter, preservar e se adequar fielmente às normas que regulamentam o espaço em que vivem.

A vantagem do emprego do contrato de cessão de uso de superfície como instrumento ágil ao controle do Estado na utilização do solo, pelas características jurídicas dinâmicas que carregam em relação à posse daquilo que é cedido e ao que se incorpora, e a não rigidez da propriedade e seus efeitos, coloca a posse de cunho social numa esfera difusa e não individual.

A conjugação homem natureza em APA exige disciplina urbanística própria que se funda basicamente em dois instrumentos: zoneamento e plano de manejo, ambos conceituados na Lei Federal no 9.985, de 18 de julho de 2000, que criou o Sistema Nacional de Unidades de Conservação da Natureza (SNUC), sendo:

- Zoneamento: definição de setores ou zonas em uma unidade de conservação com objetivos de manejo e normas específicos, com o propósito de proporcionar os meios e as condições para que todos os objetivos da unidade possam ser alcançados de forma harmônica e eficaz.

- Plano de Manejo: documento técnico mediante o qual, com fundamento nos objetivos gerais de uma unidade de conservação, se estabelece o seu zoneamento e as normas que devem presidir o uso da área e o manejo dos recursos naturais, inclusive a construção das estruturas físicas necessárias à gestão da unidade.

Pode-se afirmar que o Plano de Manejo de uma APA tem como um dos seus principais objetivos a compatibilização do regime protetivo com o regime dominial privado, preservando-se o caráter econômico da propriedade, compreendendo, aqui, as áreas dominicais destinadas à cessão da superfície do solo. É por meio desse documento que se disciplina os requisitos e os limites da construção de unidades habitacionais e das atividades econômicas permitidas.

A simples instituição de áreas de proteção ambiental sem que os recursos para a sua manutenção sejam providenciados por si só se revela, porém, insustentável. Exige-se um planejamento orçamentário que distribua melhor e de forma mais democrática os investimentos públicos em infraestrutura urbana, especialmente as que se fixam em zonas de proteção.

A urbanização desigual implica necessariamente graves problemas ambientais por força da informalidade no uso da terra, edificações em áreas inadequadas, como margens de rios e várzeas, e péssimas condições físicas e de salubridade da moradia, e tais fenômenos agravam-se em APA.

Aliás, historicamente a mera regulação-fiscalização legal é insuficiente para alterar esta realidade, no entanto a oferta adequada de moradia, somada a um contexto sólido de solidariedade e corresponsabilidade, revela-se uma contribuição legítima e efetiva para a mudança dessa realidade.

A partir da cessão do uso de superfície, o Estado deve dispor de financiamento social para que se edifiquem construções condicionadas às exigências do plano de manejo da APA, proporcionando serviços de arquitetura e engenharia apropriados, como estimulo à utilização de padrões construtivos e aportes tecnológicos que reduzam os impactos ambientais e economizem os recursos naturais, tais como captação de energia solar, captação de águas pluviais, reuso e tratamento prévio de águas, uso de materiais alternativos, dentre outras ações, traços de um desenvolvimento econômico verde.

Discorrendo sobre Economia Verde, a necessidade de construir prédios que captem água da chuva para múltiplos usos, obrigar que todas as construções novas instalem captadores de energia solar e ainda sobre contrapartidas dos atores como forma de compensações, pressupondo tais ações como um passo para a transição rumo a uma economia sustentável, ainda não alcançada (BOFF, 2014). 
Partindo da ideia central do artigo, a concessão de financiamento público ou privado deve estar condicionado às cláusulas do instrumento jurídico de cessão de uso de superfície, e as contrapartidas verificáveis por meio de ações pontuais de controle do uso do bem e sua manutenção, de forma que o superficiário se sinta parte responsável integrante no processo de uso do bem recebido e seu entorno, e não um excluído integrado de maneira injusta e pouco ou nada eficiente nas periferias das grandes cidades.

Paralelamente, o saneamento ambiental é medida legal que deve concorrer com tais ações, posto que nenhuma melhoria no quadro ambiental urbano será possível sem seu atendimento adequado.

A Lei no 11.445/07 considera como saneamento básico o abastecimento de água potável, esgotamento sanitário, limpeza urbana e a drenagem de manejo das águas pluviais urbanas, estabelecendo ainda princípios de universalização do acesso e articulação conjunta com políticas de desenvolvimento urbano, habitação, combate à pobreza, proteção ambiental e outras de relevante interesse social, voltadas à melhoria da qualidade de vida, nas quais o saneamento básico seja fator determinante.

Financiar moradia, sanear e educar, são ações que, necessariamente, impactam, em vistas dos ajustes propostos, no processo de desenvolvimento econômico das APA, sendo certo que medidas nesse sentido são bem-vindas, desde que sustentáveis, adotando o conceito de que "o desenvolvimento consiste na eliminação das privações de liberdade que limitam as escolhas e oportunidades das pessoas de exercer preponderantemente sua condição de cidadão" (SEN, 1999, p. 51).

O desenvolvimento econômico, decorrente das ações ora estudadas, tem por finalidade um bem viver do cidadão. Estrutura-se na disponibilidade do uso do solo e sua edificação pautada na efetivação de políticas públicas que exigem dos beneficiários contrapartidas vinculadas ao seu próprio desenvolvimento como pessoa humana e ao desenvolvimento de ações estruturadas pelo Estado para a consecução de tal fim, distanciando-se do cunho populista que permeou o sistema habitacional brasileiro nos últimos tempo, que desconsiderou as externalidades intrínsecas dessa demanda social e a necessária retroalimentação entre os sistemas social e natural.

Tais ações devem fazer parte de um planejamento estatal de médio e longo prazos, prevendo os parâmetros urbanísticos esperados. Planejar para remediar o passivo ambiental urbano, herdado da prática de políticas públicas equivocadas e omissas, somente contribui para a manutenção de problemas de situações de risco habitacional emergencial que prejudicam a aplicação de processos de planejamento mais participativos.

Planos diretores raramente estimam níveis de densidade desejados para a cidade e, também raramente, estabelecem parâmetros de saturação das infraestruturas. Essa discussão também se faz ausente na academia, e a programação, em termos de política econômica, da localização de investimentos, empregos, equipamentos e infraestrutura, e a elaboração de agendas de discussão com a população sobre perspectivas de longo prazo, são métodos de gestão ainda incipientes, porém, altamente desejáveis (NUNES et al., 2015).

Se na perspectiva urbanística essa ausência de um planejamento estratégico estruturado é uma realidade, na prevenção de danos ambientais tampouco se observa essa visão de médio e longo prazos pelo Estado. A avaliação ambiental estratégica deve ser utilizada, embora não obrigatória, como ferramenta para a execução de ações como a que ora se propõe.

Não se resume o instrumento às exigências de licenciamento ambiental e estudo de impacto ambiental, mas em um eficaz instrumento de gestão pública, projetando o futuro da relação do ser humano com o meio ambiente na perspectiva da avaliação do desenvolvimento econômico, dos impactos diretos e indiretos ao meio ambiente ecológico e urbano, na relação da geração futura com a alteração da natureza e, principalmente, no alinhamento dessas alterações com as políticas públicas, que envolvem os programas e planos governamentais (GODOY, 2017). Agir sem planejar é reagir. 


\section{CONCLUSÃO}

A ocupação irregular do solo em áreas de proteção ambiental é uma realidade brasileira que contribui para a degradação do meio ambiente ante a ausência da atuação do Estado, regulando e urbanizando as áreas habitadas. Dessa omissão nasce o conflito entre o direito de moradia e o meio ambiente sustentável, posto que é incompatível o fenômeno com a harmonização desses preceitos constitucionais, criando ainda obstáculos ao desenvolvimento econômico local.

Solucionar este problema de desenvolvimento urbano e ambiental é tarefa que exige do Estado planejamento estratégico estruturado em ações de médio e longo prazos com foco no uso sustentável da área ocupada, considerando que materialmente é inviável a retirada de toda a população que a ocupa irregularmente, tanto na perspectiva financeira quanto social. Não se pode porém, permitir, sob pena de incorrer em erros pretéritos, que a irregularidade se perpetue agravando os déficits socioambientais habitacionais.

É neste sentido que as Áreas de Proteção Ambiental podem oferecer em termos de ocupação regular, senão uma solução para o déficit habitacional, ao menos um alento à população menos favorecida economicamente.

Partindo-se, entretanto, da premissa de que é possível fixar o homem em APA e ali se desenvolver, inclusive economicamente de forma sustentável, deve-se exigir-lhe ações proativas de educação ambiental que lhe permita entender que estará se integrando ao sistema de forma protagonista e que dele depende a manutenção da relação ambiental equilibrada para as presentes e futuras gerações.

Assim não agindo, estar-se-ia mantendo o sistema atual de ocupação irregular do solo, atribuindo-lhe uma legalidade fictícia e pouco reveladora do seu compromisso para com o meio ambiente ecológico.

Uma vez observado que áreas dominicais podem ser objeto de contratos de cessão de uso de superfície e, por sua vez, que a incidência dessa propriedade comumente é observada em APA, o uso para a finalidade de regularização e fixação da população que vive nesses ambientes adere ao fim social que dela se espera.

A ideia do uso deste instrumento firma-se atento ao fato de não conceder ao cidadão a propriedade efetiva da terra, permanecendo a mesma no domínio do Estado, porém garantindo o direito de uso que dela flui.

Diante do desafio de se reequilibrar o meio ambiente urbano de maneira que atinja a sustentabilidade exigida no ordenamento jurídico, é dever do cidadão superficiário cumprir cláusula acidental no sentido de se envolver em projetos de educação ambiental, buscando sua autonomia e sendo crítico mediante a aquisição de conhecimentos.

Receber o solo somente, ou nele ter legitimado sua moradia, todavia, não é suficiente para atingir os fins de dignidade humana que a moradia proporciona. É necessário fomentar a reforma/construção das moradias no sentido de atender às normas previstas no plano de manejo da APA em que ele se encontra, além de se instituir uma infraestrutura de saneamento que permita atingir os fins socioambientais da localidade.

Ao construir em superfície cedida, o cidadão vincula-se mais ainda aos fins previstos no contrato na medida em que a não observância das cláusulas poderá ensejar a sua rescisão e o remanejamento de sua moradia, por não haver se adequado às normas específicas da APA onde se fixou.

Nota-se, não é um direito potestativo do Estado nesse sentido, mas uma consequência de sua inadequação. Exige-se, porém, o atuar positivo prévio do Estado, estruturando o espaço ambiental urbano e educando a população por meio dos aparelhos exigidos para a instituição da APA, especialmente a entidade gestora e seu conselho administrativo.

A ideia é demonstrar ao superficiário que ele participará deste processo de forma integrada como protagonista de uma nova e inovadora visão da propriedade, em particular rompendo o paradigma equivocado imperante de que em APA não se permite ou compatibiliza a habitação humana.

Moradia, meio ambiente equilibrado e desenvolvimento econômico são princípios intrinsecamente entrelaçados, razão pela qual a contribuição acadêmica no sentido de acenar para novos instrumentos, concentrando esforços em evidenciar a utilidade do parcelamento e cessão de superfície do solo dominical, que possam compor o planejamento estatal para o desenvolvimento sustentável urbano, ambiental e econômico, justificam o assunto estudado. 


\section{REFERÊNCIAS}

ANTUNES, Paulo de Bessa. Direito ambiental. 19. ed. rev. e atual. São Paulo: Atlas, 2017.

BRASIL. Ministério do Meio Ambiente. In: NUNES, Tarcísio et al. (org.). Sustentabilidade urbana: impactos do desenvolvimento econômico e suas consequências sobre o processo de urbanização em países emergentes: textos para as discussões da Rio+20: volume 3 habitação social e sustentabilidade. Brasília: MMA, 2015.

BRASIL. Ministério do Meio Ambiente. Zoneamento ambiental municipal. Disponível em: https://www.mma.gov.br/informma/ itemlist/category/62-planejamento-ambiental-urbano. Acesso em: 22 abr. 2020a.

BRASIL. Ministério do Meio Ambiente: Tratado de Educação Ambiental para Sociedades Sustentáveis e Responsabilidade Global. Disponível em: https://www.mma.gov.br/informma/item/8068-tratado-de-educa\%C3\%A7\%C3\%A3o-ambiental-para-sociedades-sustent\%C3\%A1veis-e-responsabilidade-global.html. Acesso em: 22 abr. 2020b.

BRASIL. Constituição da República Federativa do Brasil de 1988. 1988. Disponível em: http://www.planalto.gov.br/ccivil_03/ Constituicao/ConstituicaoCompilado.htm. Acesso em: 22 abr. 2020.

BRASIL. Lei n. 9.795, de 27 de abril de 1999. Disponível em: http://www.planalto.gov.br/ccivil_03/Leis/L9795.htm. Acesso em: 22 abr. 2020.

BRASIL. Lei n. 9.985, de 18 de julho de 2000. Disponível em: http://www.planalto.gov.br/ccivil_03/LEIS/L9985.htm. Acesso em: 22 abr. 2020.

BRASIL. Lei n. 10.257, de 10 de julho de 2001. Disponível em: http://www.planalto.gov.br/ccivil_03/leis/leis_2001/l10257.htm. Acesso em: 22 abr. 2020.

BRASIL. Lei n. 10.406, de 10 de janeiro de 2002. Disponível em: http://www.planalto.gov.br/ccivil_03/LEIS/2002/L10406.htm. Acesso em: 22 abr. 2020.

BECK, Ulrich. Sociedade de risco: rumo a uma outra modernidade. Trad. Sebastião Nascimento. 2. ed. São Paulo: Editora 34, 2011.

BOFF, Leonardo. A grande transformação: na economia, na política e na ecologia. Petrópolis: Editora Vozes, 2014.

BOFF, Leonardo. Sustentabilidade: o que é - o que não é. Petrópolis: Editora Vozes, 2012.

BONAVIDES, Paulo. Do Estado liberal ao Estado social. São Paulo: Malheiros, 2001.

BRAGA TEIXEIRA. José Guilherme. O direito real de superfície. São Paulo: Revista dos Tribunais. 1993.

DINIZ, Maria Helena. Curso de direito civil brasileiro. São Paulo: Saraiva, 2006.

GODOY, Sandro Marcos. O meio ambiente e a função social da empresa. 1. ed. Birigui: Editora Boreal, 2017.

GODOY, Sandro Marcos. Direito ambiental objetivo e descomplicado. 1. ed. Presidente Prudente: Amazon, 2020. E-Book. ISBN 978-65-00-00020-7. Disponível em: https://www.amazon.com.br/DIREITO-AMBIENTAL-OBJETIVO-DESCOMPLICADO-SANDRO-ebook/dp/B084Q6NYLL/ref=sr_1_5?qid=1587517749\&refinements=p_27\%3ASandro+Marcos+Godoy\&s=books\&sr=1-5. Acesso em: 22 abr. 2020.

GOMES. Orlando. Direito real de propriedade. São Paulo: Revista dos Tribunais, 2002.

JACOBI, P. et al. (org.). Educação, meio ambiente e cidadania: reflexões e experiências. São Paulo: SMA, 1998.

JUCÁ, Francisco Pedro. Responsabilidade social e sustentabilidade. In: MESSA, Ana Flávia; THEOPHILO NETO, Nuncio; THEOPHILO JUNIOR, Roque (org.). Sustentabilidade ambiental e os novos desafios na era digital: estudos em homenagem a Benedito Guimarães Aguiar Neto. 1. ed. São Paulo: Saraiva, 2011. V. 1.

LISBOA PESSOA, Mariana. Ocupação irregular e regularização fundiária de interesse social em áreas de proteção ambiental. 2014. Dissertação (Mestrado em Planejamento Urbano e Regional) - UFRGS, Porto Alegre, 2014.

MARQUES NETO, Floriano Azevedo. Bens públicos: função social e exploração econômica. O regime jurídico das utilidades públicas. Belo Horizonte: Fórum, 2009.

MORAES, Alexandre de. Direito constitucional. 33. ed. rev. e atual. até a EC no 95, de 15 de dezembro de 2016. São Paulo: Atlas, 2017.

NUNES, Tarcísio et al. (orgs.). Sustentabilidade urbana: impacto do desenvolvimento econômico e suas consequências sobre o processo de urbanização em países emergentes: textos para as discussões da Rio + 20. Saneamento Básico. Brasília: Ministério do Meio Ambiente - MMA, 2015. V. 2.

PAULO, Vicente; ALEXANDRINO, Marcelo. Direito constitucional descomplicado. 8. ed. São Paulo: Editora Método, 2012. PORTANOVA, R. S.; OLAVO LEITE, A.; FIGUEIREDO, M. F. (org.). Os 15 anos da Lei no 9.985, de 18 de julho de 2000. CONGRESSO DE DIREITO AMBIENTAL DAS ÁREAS PROTEGIDAS, 2., 2015, São Paulo. Anais [...]. São Paulo: Ixtlan, 2015.

REIGOTA, M. Desafios à educação ambiental escolar. In: JACOBI, P. et al. (org.). Educação, meio ambiente e cidadania: reflexões e experiências. São Paulo: SMA, 1998.

ROGERS, Richard. Cidades para um pequeno planeta. 2. ed. Portugal: Gustavo Gili, 2005.

SEN, Amartya. Os fins e os meio do desenvolvimento. Desenvolvimento como liberdade. São Paulo: Companhia das Letras, 1999.

VENOSA, Silvio de Salvo. Direito civil. 6. ed. São Paulo: Atlas, 2006. 